\title{
Ecological and functional changes associated with long-term recovery from organic enrichment
}

\author{
Catriona K. Macleod ${ }^{1,2, *}$, Natalie A. Moltschaniwskyj ${ }^{2}$, Christine M. Crawford ${ }^{1}$ \\ ${ }^{1}$ Marine Research Laboratories, Tasmanian Aquaculture and Fisheries Institute, and Aquafin CRC, University of Tasmania, \\ Hobart, Tasmania 7001, Australia \\ ${ }^{2}$ School of Aquaculture, Tasmanian Aquaculture and Fisheries Institute, University of Tasmania, Launceston, \\ Tasmania 7250, Australia
}

\begin{abstract}
The recovery of a soft sediment benthic invertebrate community from high levels of organic enrichment was evaluated after removal of farmed fish at an Atlantic salmon Salmo salar culture site in southeast Tasmania. Although the pattern of recovery followed established successional principles, after 36 mo neither communities under or at the edge of cages, nor communities $10 \mathrm{~m}$ from the edge of the cage, had attained a structure equivalent to that of the reference communities. In the first few months there was little evidence of recovery and the community was dominated by species characteristic of impacted conditions. After 12 mo the system had markedly improved, containing a diverse range of species with functional roles similar to those of the reference sites. Once the ecological function of the sediment was restored, subsequent changes in the community structure were relatively minor, simply reflecting the addition of rarer species with longer reproductive cycles and/or larval stages with a greater sensitivity to the negative effects of organic enrichment. These species may be significant where specific community changes, loss of diversity or the possibility of species extinction are the critical issues. However, restoration of system function may be a more useful indicator of generalized recovery from organic enrichment than of community equivalence.
\end{abstract}

KEY WORDS: Benthic recovery · Functional ecology · Recolonisation • Organic enrichment · Macrofauna $\cdot$ Aquaculture

\section{INTRODUCTION}

Recovery of species diversity or faunal abundance, restoration of particular species or community types or full community equivalence with unaffected conditions are all valid criteria for the determination of recovery, but have very different recovery time frames, with full community recovery likely to provide the most conservative estimates. Knowing when particular components of the community become re-established may be an important measure of recovery where biodiversity is the main issue, or where rare or endangered species are a particular concern. Consequently, when comparing recovery rates it is important to ensure that the underlying measure is equivalent. When making management decisions regarding recovery it is important to be clear on the level of recovery upon which those decisions are being made and to establish a priori what is meant by recovery.

The classic studies by Pearson \& Rosenberg (1978) and Rhoads et al. (1978) define temporal and spatial successional patterns associated with organic enrichment, identifying 'indicator' species or community types that reflect particular successional stages of disturbance and recovery. The identification of these indicator species and their role in the recovery process remains a cornerstone of both basic and applied studies of benthic recolonisation (Whitlach et al. 2001). However, with the exception of the opportunistic polychaete species, Capitella capitata, these indicator species are not well known in southern temperate regions.

In Tasmania the overall trends in response to organic enrichment are similar to those observed in northern hemisphere, but Macleod et al. (2004) suggested that 
there is a marked difference between the absolute levels of the geochemical indicators and the extent of effects inferred by the changes in the community structure. As a result the biological response of the Tasmanian fauna appears to be much greater for a lesser chemical impact than observed in the northern hemisphere, suggesting that geographic location can have a significant influence on recovery response. However, the study by Macleod et al. (2004) did not specifically examine the faunal relationships and so did not distinguish specific ecological changes associated with the key stages in recovery.

Many other factors can also influence the recovery response. Clearly the nature, frequency and size of the effect will all have important consequences for subsequent recovery (Zajac et al. 1998). Hydrodynamic condition is also a critical factor and will have a major influence on recovery rate (Black 2001). Local sediment conditions will significantly affect the benthic ecology, determining the community composition and the system's capacity to respond to environmental stressors (Snelgrove \& Butman 1994), which will in turn determine the functional attributes of the communities such as the mechanisms for resource partitioning and utilisation, predator avoidance and defence, and reproduction (Pearson 2001). The resilience of the background community is of particular importance in determining recovery response (Bonsdorff 1989). Some early colonizing 'pioneering' species have life history characteristics that facilitate rapid responses in recently perturbed areas, while late successional 'equilibrium' species are more constrained in their population responses and have slower recolonisation rates (Whitlach et al. 2001). Species interactions may facilitate or inhibit successional changes (Connell \& Slatyer 1977). All of these interactions can be affected by the timing of the disturbance event.

The amount of time actually required for sustainable sediment remediation is poorly understood at present. However, if we accept the assertion that once a system is functionally recovered it will progress to an 'equilibrium' community providing no further perturbation is encountered (Young et al. 2001), then remediation should be sustainable once sediment function is restored. Consequently, individual species identities become less important and the ecological function of the species in relation to the particular successional stage with which it is associated becomes the issue of interest (Rhoads \& Germano 1986). This, in turn, suggests that the sustainability of ongoing and repetitive impacts, such as those generated by fish farming may be better assessed by establishing whether the ecological function of the system has been restored.

This study is a continuation of previous work (Macleod et al. 2004), which examined the rate at which sediments recovered after the cessation of organic enrichment, and focuses on the significance of the biological changes occurring through the recovery process. The main aims of this study were to improve our understanding of local ecological changes by identifying the resident taxa associated with the critical successional stages and to define the functional significance of those species in the recolonisation and successional processes.

\section{MATERIALS AND METHODS}

The location and farming history of the study area and sampling locations are described in Macleod et al. (2004). Two cage locations with comparable farming histories, i.e. equivalent Atlantic salmon Salmo salar biomass and feeding levels, were selected at random for this study. At each cage samples were collected from within the cage area and at $10 \mathrm{~m}$ beyond the cage, and the positions of the sampling stations were fixed with a transect line and markers. Studies of the effect of fish farming in Tasmania showed no detectable ecological effects on the benthos $35 \mathrm{~m}$ beyond the cage boundary (Edgar et al. 2005); therefore, replicate samples were collected from reference stations located $150 \mathrm{~m}$ from the cages, directly in line with the fixed transects and at similar depths.

Benthic samples were collected by a diver at each station $2 \mathrm{wk}$ after removal of the fish and then $1,2,6$, 12, 24 and 36 mo after removal. Five replicates were collected haphazardly from within $1 \mathrm{~m}$ of each station using a $150 \mathrm{~mm}$ diameter PVC pipe corer to a depth of $100 \mathrm{~mm}$ (area of $0.018 \mathrm{~m}^{2}$ ). Samples were transferred immediately to mesh bags $\left(0.875 \mathrm{~mm}^{2}\right.$ mesh). The bags were rinsed on the boat and transferred to containers with $40 \%$ formalin in seawater. In the laboratory each sample was sieved to $1 \mathrm{~mm}$, sorted and the animals retained were identified to the lowest possible taxonomic level and enumerated. Samples were grouped as representative of direct cage effects $(0 \mathrm{~m})$, indirect farm effects $(10 \mathrm{~m})$ and unaffected reference conditions $(150 \mathrm{~m})$.

Multivariate analyses of community data was undertaken using PRIMER ${ }^{\odot}$ (2006). The data used were the mean values of the replicates for each site. Means were square root transformed to adjust the importance of species dominance and a Bray-Curtis similarity matrix was used to determine the relationships among the community structures of unaffected (reference) stations, with stations subject to direct and indirect effects using non-metric multidimensional scaling (NMDS). The significance of differences in the macrofaunal data between the stations over time was evaluated using planned comparisons in the analysis of similarities (ANOSIM) randomization test. SIMPER analysis was 
used to determine whether any particular species or factors were indicative of these patterns.

Basic life history characteristics (feeding strategy, function in sediment and reproductive strategy) were assigned to the main species determined by SIMPER analysis to define the community groups. Feeding strategies were predatory carnivores/omnivores (PO), suspension feeders (SF), deposit feeders (DF) or epibenthic feeders (EP). However, it is recognized that many species change their feeding strategies in response to environmental conditions and where this was deemed to be the case, a range of strategies have been indicated or they are classed as having a variable feeding strategy (VF). Bioturbation capacity was defined in relatively simple terms as whether the animals were sediment destabilisers (DS) or stabilisers (ST) and was determined by reference to the known ecology of the species or of that of the nearest relative. Where possible the main reproductive strategy of each species was characterised by whether adults had staged/periodic (SR) or pioneering/opportunistic (OR) reproductive cycles and whether larvae were benthic (B) or pelagic (P). Australian marine and estuarine infauna is relatively poorly described, with very little species-specific biological and ecological information. Where the ecology or biology of a species or taxon was not specifically known it was inferred using information from the next closest species or taxonomic group. Principal components analysis (PCA) of the life history data was used to compare cage, farm and reference positions.

\section{RESULTS}

The infaunal communities within cages were significantly different from the reference communities $(25 \mathrm{~m}$ sites) at both farms throughout the $36 \mathrm{mo}$, whilst there was a broad similarity in the communities among the reference sites (Table 1). The cluster analysis generated 3 groups (A, B and C) at an overall similarity level of $36 \%$ (Fig. 1). Station-time combinations in Group A were strongly dominated by Capitella capitata complex and Malacoceros tripartitus (Table 2)-polychaete species most commonly associated with anaerobic conditions (Macleod et al. 2004, 2007) — and it was deemed that Group A was markedly impacted. This group included the initial cage position (0.5 to $2 \mathrm{mo}$ ) and the farm position at 24 mo. Group B sites/times were characterised by the bivalve, Theora fragilis, and the ostracod, Euphilomedes sp.1 (Table 2). Theora fragilis is typical of intermediately affected communities (Macleod et al. 2007). C. capitata was still present in these samples, albeit in considerably reduced abundance, and the introduced bivalve, Corbula gibba, and the opportunistic whelk, Nassarius nigellus, commonly
Table 1. Planned 1-way ANOSIM comparisons between cage (C), farm (F) and reference (R) communities at each sample time. In all cases 999 permutations were undertaken. Bold: significant $(p<0.05)$. Codes under planned contrast represent time post-farming (from 0.5 to $36 \mathrm{mo}$ ) and location (C, F or R)

\begin{tabular}{|lcc|}
\hline Planned contrast & R statistic & $\mathrm{p}$ \\
\hline $0.5-\mathrm{R}, 1-\mathrm{R}$ & -0.076 & 0.875 \\
$1-\mathrm{R}, 2-\mathrm{R}$ & -0.001 & 0.473 \\
$2-\mathrm{R}, 12-\mathrm{R}$ & 0.206 & 0.053 \\
$12-\mathrm{R}, 24-\mathrm{R}$ & 0.084 & 0.195 \\
$24-\mathrm{R}, 36-\mathrm{R}$ & 0.348 & $\mathbf{0 . 0 0 6}$ \\
& & \\
0.5-C, 0.5-R & 0.878 & $\mathbf{0 . 0 0 1}$ \\
1-C, 1-R & 0.539 & $\mathbf{0 . 0 0 1}$ \\
$2-\mathrm{C}, 2-\mathrm{R}$ & 0.583 & $\mathbf{0 . 0 0 1}$ \\
$12-\mathrm{C}, 12-\mathrm{R}$ & 0.782 & $\mathbf{0 . 0 0 1}$ \\
$24-\mathrm{C}, 24-\mathrm{R}$ & 0.539 & $\mathbf{0 . 0 0 2}$ \\
$36-\mathrm{C}, 36-\mathrm{R}$ & 0.730 & $\mathbf{0 . 0 0 2}$ \\
& & \\
$0.5-\mathrm{F}, 0.5-\mathrm{R}$ & 0.502 & $\mathbf{0 . 0 0 1}$ \\
1-F, 1-R & 0.397 & $\mathbf{0 . 0 0 1}$ \\
$2-\mathrm{F}, 2-\mathrm{R}$ & 0.605 & $\mathbf{0 . 0 0 1}$ \\
$12-\mathrm{F}, 12-\mathrm{R}$ & 0.529 & $\mathbf{0 . 0 0 2}$ \\
$24-\mathrm{F}, 24-\mathrm{R}$ & 0.217 & $\mathbf{0 . 0 4 5}$ \\
$36-\mathrm{F}, 36-\mathrm{R}$ & 0.503 & $\mathbf{0 . 0 0 2}$ \\
\hline
\end{tabular}

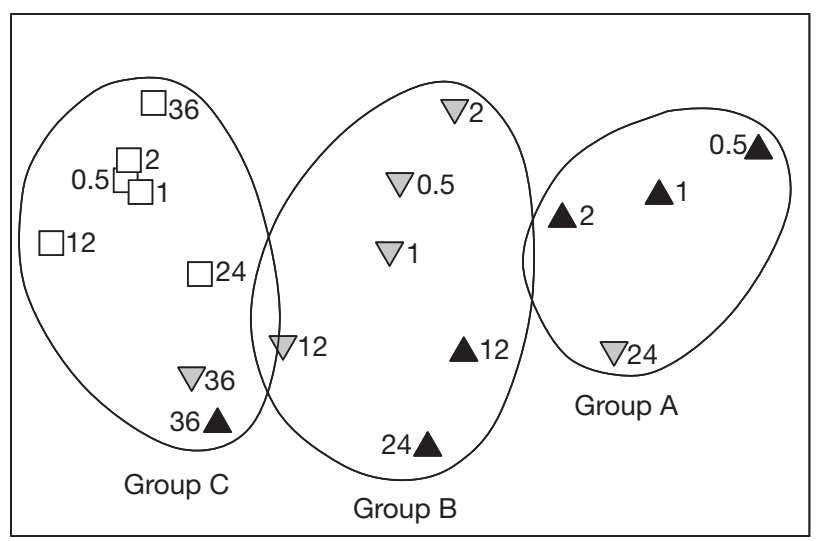

Fig. 1. NMDS ordination of relationships between benthic faunas sampled at cage $(\boldsymbol{\Delta})$, farm $(\nabla)$ and reference $(\square)$ locations over 36 mo (stress $=0.11$ ), with cluster groups identified at $36 \%$ overall similarity indicated. Numbers: time (mo) after removal of cages

associated with areas of moderate impact (Macleod et al. 2004), were also prominent components of these communities. Therefore, it was determined that this group was moderately impacted. Group B contained most of the farm positions and the cage positions at 12 and $24 \mathrm{mo}$. Position/times in Group C were characterised by a broader group of species including the terrebellid polychaete, Lysilla jennacubinae, and the brittlestar, Amphiura elandiformis, both of which are indicative of unimpacted conditions (Edgar et al. 2005, Macleod et al. 2007). 
Table 2. Average abundance (ind. $\mathrm{m}^{-2}$ ) and contribution to group similarity of the characterising species (i.e. species comprising $90 \%$ of the within-group similarity for each of the cluster groups distinguishable at $>40 \%$ overall similarity) for each community group. Codes under group name represent time postfarming (from 0.5 to $36 \mathrm{mo}$ ) and location (C, F or R)

\begin{tabular}{|c|c|c|c|}
\hline & Species & $\begin{array}{l}\text { Average } \\
\text { abun- } \\
\text { dance }\end{array}$ & $\begin{array}{c}\text { Contribution } \\
\text { to similarity } \\
(\%)\end{array}$ \\
\hline $\begin{array}{l}\text { Group A } \\
\text { (0.5-C, 1-C, 2-C, 24-F) } \\
\text { Average similarity: } 60.52\end{array}$ & $\begin{array}{l}\text { Capitella capitata } \\
\text { Malacoceros tripartitus } \\
\text { Theora fragilis } \\
\text { Prionospio kulin } \\
\text { Euphilomedes sp. } 1 \\
\text { Corbula gibba } \\
\text { Nassarius nigellus } \\
\text { Simplisetia amphidonta }\end{array}$ & $\begin{array}{r}1701 \\
140 \\
29 \\
25 \\
31 \\
18 \\
18 \\
11\end{array}$ & $\begin{array}{r}53.17 \\
10.17 \\
5.96 \\
5.56 \\
5.40 \\
4.36 \\
4.02 \\
4.02\end{array}$ \\
\hline $\begin{array}{l}\text { Group B } \\
(0.5-\mathrm{F}, 1-\mathrm{F}, 2-\mathrm{F}, 12-\mathrm{C} \\
4-\mathrm{C}, 12-\mathrm{F}) \\
\text { Average similarity: } 47.29\end{array}$ & $\begin{array}{l}\text { Theora fragilis } \\
\text { Euphilomedes sp. } 1 \\
\text { Corbula gibba } \\
\text { Nassarius nigellus } \\
\text { Nemertea sp. } 1 \\
\text { Prionospio kulin } \\
\text { Simplisetia amphidonta } \\
\text { Capitella capitata } \\
\text { Amphiura elandiformis } \\
\text { Phoronida sp. } 1 \\
\text { Mysella donaciformis }\end{array}$ & $\begin{array}{r}121 \\
96 \\
19 \\
21 \\
9 \\
15 \\
10 \\
9 \\
4 \\
2 \\
2\end{array}$ & $\begin{array}{r}27.39 \\
23.18 \\
7.51 \\
7.25 \\
5.86 \\
5.27 \\
4.36 \\
4.32 \\
2.32 \\
1.56 \\
1.43\end{array}$ \\
\hline $\begin{array}{l}\text { Group C } \\
\text { (0.5-R, 1-R, 2-R, 12-R, } \\
\text { 24-R, 6-R, 6-F, 36-C) } \\
\text { Average similarity: } 50.80\end{array}$ & $\begin{array}{l}\text { Lysilla jennacubinae } \\
\text { Euphilomedes sp. } 1 \\
\text { Nassarius nigellus } \\
\text { Theora fragilis } \\
\text { Nucula pusilla } \\
\text { Amphiura elandiformis } \\
\text { Corbula gibba } \\
\text { Lumbrinereis sp. } 1 \\
\text { Euphilomedes sp. } 2 \\
\text { Euchone limnicola } \\
\text { Chaetozone setosa }\end{array}$ & $\begin{array}{r}34 \\
24 \\
20 \\
25 \\
34 \\
30 \\
9 \\
11 \\
7 \\
4 \\
4\end{array}$ & $\begin{array}{r}13.43 \\
11.31 \\
10.28 \\
9.51 \\
9.16 \\
7.82 \\
7.61 \\
7.17 \\
6.74 \\
4.05 \\
3.07\end{array}$ \\
\hline
\end{tabular}

The life histories of the dominant species (i.e. those comprising $>90 \%$ of the overall similarity) within the impacted (cages 0.5 to $2 \mathrm{mo}$ ) and reference communities provide important information on the ecological significance of the community changes (Table 3 ). The reference communities contained species with a diverse range of life histories. In contrast there was markedly less functional variability in the impacted communities. There were fewer STs or SFs, both in terms of abundance and number of species, in the impacted communities, but the proportion of taxa (species and abundance) with OR strategies was much greater. Nemerteans and echinoderms were important taxa in the reference communities, but played little part in the communities at the impacted sites where the species mix and abundance was dominated by annelids.

The greatest change in ecological function was associated with the cage communities in the initial recovery phase (i.e. cluster group A) (Fig. 2a,c). More than $95 \%$ of the total variability in the full data set was associated with changes between these initial communities and the remaining sites and times (first principal component, PC1). These initial communities were functionally very different to both the references and to most of the cage and farm positions sampled later in the study (Figs. 2a,c). Deposition of fouling material (i.e. algae and mussels) from lines close to one of the farm cages resulted in a greater than expected effect in the farm communities at $24 \mathrm{mo}$. The affected communities were dominated (both numerically and in number of taxa) by small to medium sized DFs, which would destabilize the upper sediments (Table 3). On the whole these species were opportunistic with the ability to rapidly reproduce and colonise, producing both B and P larvae (Fig. 2c). After 12 mo the function of the cage communities appeared to have largely returned to that of the reference communities (Figs. 2a,c).

Exclusion of the data for the most affected positions (Group A) from the analysis allows both the functional differences between the remaining communities and the subsequent recovery response to be examined more closely (Figs. 2b,d). PC1 accounts for almost $50 \%$ of the overall variability and associated with it, a strong gradient in functional response remains. The reference communities are positioned on the right of the plots whilst the earlier farm positions appear on the left. The sediment function of these positions separated along this impact gradient in much the same way as in the complete dataset. The farm positions (i.e. the more impacted end of the gradient) continued to contain a greater proportion of small to medium sized deposit feeding sediment destabilisers than did the reference communities, which had comparatively more suspension feeding and epibenthic sediment stabilizers (Fig. 2d). However, the gradient in reproductive function was slightly different. In numerical terms, the farm positions were most strongly associated with taxa where SR reproduction and production of P larvae are the reproductive strategies (Fig. $2 \mathrm{~d}$ ). The communities at the cage position at $12 \mathrm{mo}$ were more strongly associated with OR strategies. An increased prevalence and abundance of taxa with SR reproductive strategies resulted in the somewhat anomalous association of the reference position at 36 mo with the early farm positions rather than with the other reference samples. 
Table 3. Abundance, ecological function and reproductive strategies of the species that contributed most to the overall group similarity of the reference and impacted (cages 0.5-2 mo post-farming) communities. Ecological function has been derived from literature sources. Italics: nearest taxonomically similar species/group (no species-specific information available). Key to ecological function: $\mathrm{LG}=$ large bodied animal (likely to be retained on a $10 \mathrm{~mm}$ sieve), $\mathrm{MD}=$ medium sized animal (retained on a $4 \mathrm{~mm}$ sieve), $\mathrm{SM}=$ small animal (retained on a $1 \mathrm{~mm}$ sieve), $\mathrm{SF}=$ suspension feeder, $\mathrm{DF}=$ deposit feeder, $\mathrm{C}=$ carnivorous, $\mathrm{ST}=\mathrm{sediment}$ stabiliser, DS = sediment destabiliser, $\mathrm{E}=$ epibenthic. Key to reproductive strategy: $\mathrm{SG}=$ single staged generation, $\mathrm{MG}=\mathrm{multiple}$ generations, $\mathrm{P}=$ planktonic juveniles, $\mathrm{B}=$ benthic larvae, $\mathrm{SR}=$ staged reproductive cycle, $\mathrm{OR}=$ opportunistic re-productive cycle, ID = indeterminate reproductive strategy

\begin{tabular}{|c|c|c|c|c|c|}
\hline Species & Phylum & $\begin{array}{l}\text { Percentage } \\
\text { similarity } \\
\text { contribution }\end{array}$ & $\begin{array}{l}\text { No. of } \\
\text { ind. } \mathrm{m}^{-2}\end{array}$ & Ecological function & $\begin{array}{l}\text { Reproductive } \\
\text { strategy }\end{array}$ \\
\hline \multicolumn{6}{|c|}{ Reference (average group similarity $=31.63$ ) } \\
\hline Nucula pusilla & Mollusca & 24.71 & 73 & $\mathrm{LG}, \mathrm{DF}, \mathrm{DS}$ & $\mathrm{MG}, \mathrm{P}, \mathrm{SR}$ \\
\hline Lysilla jennacubinae & Annelida & 21.19 & 57 & $\mathrm{LG}, \mathrm{DF}, \mathrm{ST}$ & ID \\
\hline Amphiura elandiformis & Echinodermata & 17.55 & 46 & LG, DF/SF, DS & $M G, P, S R$ \\
\hline Euphilomedes sp. 1 & Crustacea & 6.47 & 24 & SM, DF, DS & ID \\
\hline Lumbrinereis sp. 1 & Annelida & 4.89 & 15 & LG, DF, DS & $\mathrm{SG}, \mathrm{B}, \mathrm{SR}$ \\
\hline Nemertea sp & Nemertea & 4.49 & 14 & $\mathrm{MD}, \mathrm{C} / \mathrm{DF}, \mathrm{DS}$ & $\mathrm{MG}, \mathrm{B}, \mathrm{SR}$ \\
\hline Corbula gibba & Mollusca & 4.49 & 14 & $\mathrm{MD}, \mathrm{DF}, \mathrm{DS}$ & $M G, P, S R$ \\
\hline Chaetozone setosa & Annelida & 3.76 & 8 & SM, SF, ST/DS & ID \\
\hline Nassarius nigellus & Mollusca & 3.65 & 9 & $\mathrm{MD}, \mathrm{DF}, \mathrm{E}$ & $\mathrm{MG}, \mathrm{B}, \mathrm{SR}$ \\
\hline \multicolumn{6}{|c|}{ Impacted (average group similarity $=\mathbf{2 7 . 9 3}$ ) } \\
\hline Capitella capitata (complex) & Annelida & 61.64 & 1766 & $\mathrm{SM}, \mathrm{DF}, \mathrm{DS}$ & $\mathrm{MG}, \mathrm{B} / \mathrm{P}, \mathrm{OR}$ \\
\hline Malacoceros tripartitus & Annelida & 12.02 & 226 & $\mathrm{MD}, \mathrm{DF}, \mathrm{DS}$ & $\mathrm{MG}, \mathrm{OR}$ \\
\hline Prionospio kulin & Annelida & 7.63 & 45 & $\mathrm{MD}, \mathrm{DF}, \mathrm{DS}$ & $\mathrm{SG}, \mathrm{P}$ \\
\hline Euphilomedes sp. 1 & Crustacea & 5.09 & 15 & SM, DF, DS & ID \\
\hline Theora fragilis & Mollusca & 3.56 & 18 & $\mathrm{MD}, \mathrm{DF}, \mathrm{DS}$ & $\mathrm{MG}, \mathrm{P}, \mathrm{SR}$ \\
\hline Nassarius nigellus & Mollusca & 2.08 & 7 & $\mathrm{MD}, \mathrm{DF}, \mathrm{E}$ & $\mathrm{MG}, \mathrm{B}, \mathrm{SR}$ \\
\hline
\end{tabular}

\section{DISCUSSION}

This study identified marked differences in sediment recovery response after organic enrichment. The findings suggest that ecosystem rehabilitation may be more effectively defined by restoration of ecological function than by recovery of species composition. In the first few months post-farming the cage conditions were affected and the community was dominated by 2 polychaete species, Capitella capitata and Malacoceros tripartitus; both are opportunists able to tolerate extremely high levels of organic carbon and increased sedimentation rates (e.g. Johannessen et al. 1994; Levin 2000). Although C. capitata and M. tripartitus initially defined the cage communities, after 12 mo both species were almost absent from the cage communities, indicating improved environmental conditions. Recovery in the benthic infaunal community structure over the fallow period followed a gradient consistent with established models (Pearson \& Rosenberg 1978, Rhoads et al. 1978).

As the sediment conditions improved the abundance of the impact indicators declined and overall diversity increased. The transitional communities represented a broad continuum of change; therefore, it was difficult to identify species representative of the whole community. However, the abundance of some species increased during the initial recovery period relative to the impacted community. The native dog whelk Nassarius nigellus, a common epibenthic scavenger, was amongst the first species to return to the cage sediments, taking advantage of the increased food supply. However, abundances declined towards the end of the study, presumably as resources became depleted. The introduced bivalve, Theora lubrica, is a selective deposit-feeder, which is also relatively tolerant of organic pollution, hypoxic conditions and high levels of sedimentation (Tamai 1996, Saito et al. 1998, Talman 1998). This species colonized the affected sites quickly after farming stopped, and was more common in recovering sediments than in either impacted or reference communities, but also declined as sediment conditions returned to normal. Consequently, the presence of these species in increasing abundance after cessation of impact may be indicative of the transitional community and the onset of recovery.

The reference communities contained several species from taxa known to be relatively long lived, which can take several years to mature. Brittlestars of the genus Amphiura can have life spans in excess of 10 yr (O'Connor et al. 1983, Munday \& Keegan 1992, Sköld et al. 2001) and may not become reproductively mature until they are 3 to 4 yr old (Fish \& Fish 1996, Sköld et al. 2001). Species of Nucula may also live for more than 10 yr (Wilson 1992) and may not mature until their 2nd year (Davis \& Wilson 1983). Studies of 

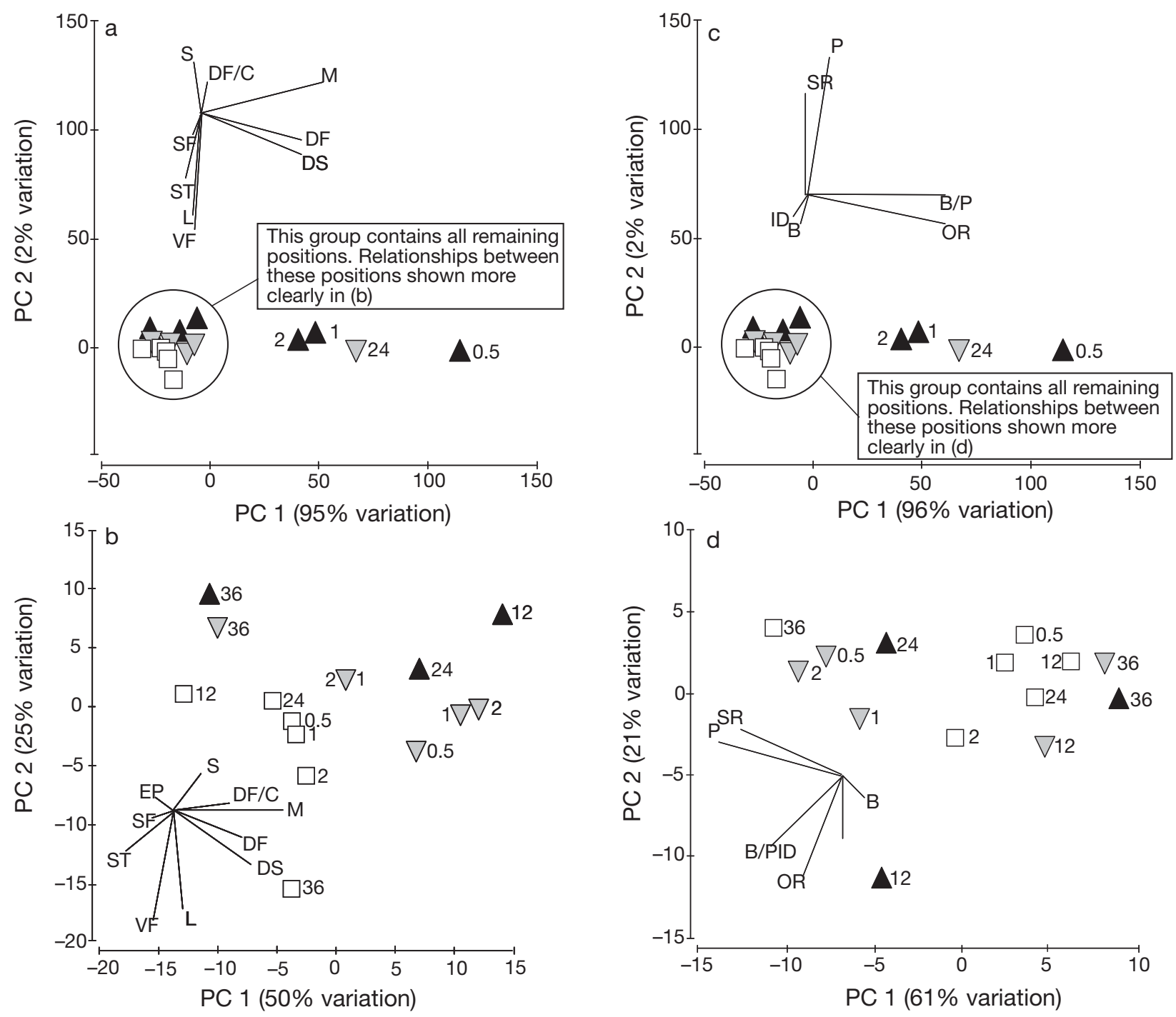

Fig. 2. Principle coordinates analysis with biplot showing $(\mathrm{a}, \mathrm{b})$ sediment functions and $(\mathrm{c}, \mathrm{d})$ reproductive strategies most strongly associated with site separations of reference $(\square)$, farm $(\nabla)$ and cage $(\boldsymbol{\Delta})$ locations for the dominant taxa over time using $(\mathrm{a}, \mathrm{c})$ all sample locations and $(b, d)$ excluding the most affected locations. The proportion of the overall variability explained by each principal component is indicated on the relevant axis. Key sediment functions - S, M, L: small, medium or large bodied animals, respectively; DS: sediment destabilisers, ST: sediment stabilisers, C: predatory carnivores, SF: suspension feeders, DF: deposit feeders, EP: epibenthic feeders, VF: taxa with a variable feeding strategy. Reproductive strategies - SR, OR, ID: staged, opportunistic, or indeterminate reproductive cycles, respectively; B, P: benthic or pelagic larvae, respectively. Numbers indicate the month that samples were taken

recovery after fish farming indicate that affected sites may not be fully recovered (i.e. returned to reference community structure) after 36 mo (Macleod et al. 2004), and complete recovery can take many months (e.g. Johannessen et al. 1994, Pereira et al. 2004) or even years (Karakassis et al. 1999, Brooks et al. 2003, 2004). Given that complete recovery requires the full re-establishment of the community that existed before the disturbance, how quickly this occurs will be determined by the nature and resilience of the natural background community (Bonsdorff 1989) and will take as long as the life cycle of the longest-lived taxa in that community.

Reference communities had a diverse fauna containing many species sensitive to the adverse effects of organic enrichment. Four of the dominant species in this community: the brittle star, Amphiura elandiformis, 2 polychaetes, Lysilla jennacubinae and Lumbrineris sp. 1, and a bivalve, Nucula pusilla, would be highly susceptible to the direct effects of organic enrichment, as they are intolerant of low oxygen levels and high sedimentation (Hutchings 2000, Paxton 2000). The re- 
productive ecology of these species would then affect their ability to re-establish after impact. Amphiura generally have $\mathrm{P}$ larvae and a periodic reproductive cycle (Bowner 1982, Pedrotti 1993). Similarly, terrebelids tend to have a relatively restricted spawning season of a few days or weeks (Hutchings 2000), whilst lumbrinerids tend to be fairly long lived with poor fecundity (Fauchald 1983). As a consequence all of these species would be slow to recolonise.

Many reference species returned soon after active enrichment ceased at the cage and farm locations. This may be due to migration of juveniles and adults, which is the most common process of early recolonisation and is important for species with late successional stage life history traits (Whitlach et al. 2001). However, the environmental sensitivities of adult and larval stages can be very different, with larval stages often less tolerant (Snelgrove \& Butman 1994, Pearson 2001). Larval recolonisation often includes a broader range of species than is available from direct immigration and some of these species may be better adapted to the prevailing environmental conditions than the existing fauna (Thrush \& Whitlach 2001). This might explain the decline in the number of reference species and increase in other taxa at the cage and farm locations in 2nd and 3rd years. Where recovery is particularly rapid, occurring within only a few weeks or months (e.g. Ritz et al. 1989, Lu \& Wu 1998), it may be that only migration of fauna occurred in this instance. This raises some interesting issues about how recovery is evaluated and at what point recovery is determined to have occurred. Where there is a possibility of regression or a divergence in the recovery trajectory, studies of recovery need to be undertaken over a sufficient temporal scale to determine whether community changes are sustained. Under these circumstances ecological function may be a more robust measure of recovery.

Absence of equilibrium species may be important in the overall biodiversity of the system, but may not be as important in defining the overall function of the system. The main ecological functions were reestablished at the cage locations after $12 \mathrm{mo}$, which is broadly equivalent to the point at which the sediment chemistry recovered (Macleod et al. 2004). This suggests that once the sediment chemistry has recovered, then without further perturbation there would be potential for functional recovery. Although the length of time required for full recovery may vary, once the recovery process starts the system should progress to an equilibrium stage providing no further perturbation is encountered (Young et al. 2001). Consequently, functional recovery of the system may be a more useful reference point for establishing and managing ecological recovery than restoration of community composition, as functional recovery suggests that the balance of the ecological processes within the system has returned. At 12 mo the cage locations were functionally similar to reference sites, in terms of the bioturbation, feeding and reproductive strategies. However, at this point only $53 \%$ of the species had become reestablished, suggesting that there was a large amount of redundancy in the functional roles of many species. Although the taxa associated with each stage in the enrichment models will vary with geographic location, the organism-sediment relationships and changes in trophic structure appear to be similar (Pearson \& Rosenberg 1978, Rhoads \& Germano 1982, Pearson 2001). The primary difficulty with assessing communities based on the functional characteristics of the species is obtaining sufficient biological and ecological information about the fauna to correctly assign life history traits. In this study the fauna was dominated by 10 species where the ecology and biology, or at least that of taxonomically similar species, was quite well known.

The findings of this study identify some important points for environmental managers to consider. The criteria used to define recovery must be clear and relevant to the environmental management goals. Furthermore, differences in the successional end points of natural communities will markedly affect the time frame over which recovery should be assessed; consequently the ecology of the reference environment needs to be properly understood. Ultimately, when assessing recovery, it is the functional recovery that may represent the critical reference point. Where no further impacts on the environment are expected, functional recovery may be considered to represent the point at which a system has demonstrated its capacity to recover based on the biological characteristics of the community.

Acknowledgements. This work was undertaken with the support of Aquatas and the Tasmanian Department of Primary Industries, Water and Environment. We particularly acknowledge the field and laboratory assistance of B. Connell, S. Dickson and I. M. Mitchell.

\section{LITERATURE CITED}

Black KD (2001) Environmental impacts of aquaculture. Sheffield Academic Press, Sheffield

Bonsdorff E (1989) Infaunal colonization and its dependence on environmental variation - experimental evidence from the northern Baltic Sea. In: Ryland JS, Tyler, PA (eds) Reproduction, genetics and distribution of marine organisms. 23rd Eur Mar Biol Symp, Olsen and Olsen, Fredensborg, p 349-356.

> Bowner T (1982) Reproduction in Amphiura filiformis (Echinodermata: Ophiuroidea): seasonality in gonad development. Mar Biol 69:281-290

Brooks KM, Stierns AR, Mahnken CVW, Blackburn DB (2003) Chemical and biological remediation of the benthos near Atlantic salmon farms. Aquaculture 219:355-377 
Brooks KM, Stierns AR, Backman C (2004) Seven year remediation study at the Carrie Bay Atlantic salmon (Salmo salar) farm in the Broughton Archipelago, British Columbia, Canada. Aquaculture 239:81-123

Connell JH, Slatyer RO (1977) Mechanisms of succession in natural communities and their role in community stability and organization. Am Nat 111:1119-1144

Davis JP, Wilson JG (1983) The population structure and ecology of Nucula turgida (Leckenby \& Marshall) in Dublin Bay. Prog Underw Sci 8:53-60

Edgar GJ, Macleod CK, Mawbey RB, Shields D (2005) Broadscale effects of marine salmonid aquaculture on macrobenthos and the sediment environment in southeastern Tasmania. J Exp Mar Biol Ecol 327:70-90

Fauchald K (1983) Life diagram patterns in benthic polychaetes. Proc Biol Soc Wash 96:160-177

Fish JD, Fish S (1996) A student's guide to the seashore, 2nd edn. Cambridge University Press, Cambridge

Hutchings PA (2000) Family Terebellidae. In: Beesley PL, Ross GJB, Glasby CJ (eds) Polychaetes and allies: the southern synthesis. Fauna of Australia, Vol 4A: Polychaetea, Myzostomida, Pogonophora, Echiura, Sipuncula. CSIRO Publishing, Melbourne, p 226-232

Johannessen PJ, Botnen HB, Tvedten OF (1994) Macrobenthos: before, during and after a fish farm. Aquacult Fish Manag 25:55-66

Karakassis I, Hatziyanni E, Tsapakis M, Plaiti W (1999) Benthic recovery following cessation of fish farming: a series of successes and catastrophes. Mar Ecol Prog Ser 184:205-218

Levin LA (2000) Polychaetes as environmental indicators: response to low oxygen and organic enrichment. Bull Mar Sci 67:668-678

Lu L, Wu RSS (1998) Recolonisation and succession of marine macrobenthos in organic-enriched sediment deposited from fish farms. Environ Pollut 101:241-251

Macleod CK, Crawford CM, Moltschaniwskyj NA (2004) Assessment of long term change in sediment condition after organic enrichment: defining recovery. Mar Pollut Bull 49:79-88

Macleod CK, Moltschaniwskyj NA, Crawford CM, Forbes SE (2007) Biological recovery from organic enrichment: some systems cope better than others. Mar Ecol Prog Ser 342: $41-53$

Munday BW, Keegan BF (1992) Population dynamics of Amphiura chiajei (Echinodermata: Ophiuroidea) in Killary Harbour, on the west coast of Ireland. Mar Biol 114: 595-605

O'Connor B, Bowmer T, Grehan A (1983) Long-term assessment of the population dynamics of Amphiura filiformis (Echinodermata: Ophiuroidea) in Galway Bay (west coast of Ireland). Mar Biol 75:279-286

Paxton H (2000) Family Lumbrinereidae. In: Beesley PL, Ross GJB, Glasby CJ (eds) Polychaetes and allies: the southern synthesis. Fauna of Australia, Vol 4A: Polychaetea, Myzostomida, Pogonophora, Echiura, Sipuncula. CSIRO Publishing, Melbourne, p 96-97

Pearson TH (2001) Soft-sediment marine benthos: the role of bioturbation. Oceanogr Mar Biol Annu Rev 39:233-267

Initial editorial responsibility: Howard Browman, Storebø, Norway; Final editorial responsibility: Matthias Seaman, Oldendorf/Luhe, Germany
Pearson TH, Rosenberg R (1978) Macrobenthic succession in relation to organic enrichment and pollution of the marine environment. Oceanogr Mar Biol Annu Rev 16:229-311

Pedrotti ML (1993) Spatial and temporal distribution and recruitment of echinoderm larvae in the Lingurian Sea. J Mar Biol Assoc UK 73:513-530

- Pereira PMF, Black KD, McLusky DS, Nickell TD (2004) Recovery of sediments after cessation of marine fish farm production. Aquaculture 235:315-330

Rhoads DC, McCall PL, Yingst JY (1978) Disturbance and production on the estuarine seafloor. Am Sci 66:577-586

Rhoads DC, Germano JD (1982) Characterization of organism-sediment relations using sediment profile imaging: an efficient method of remote ecological monitoring of the seafloor (Remots ${ }^{\mathrm{TM}}$ system). Mar Ecol Prog Ser 8: 115-128

Rhoads DC, Germano JD (1986) Interpreting long-term changes in benthic community structure: a new protocol. Hydrobiologia 142:291-308

> Ritz DA, Lewis ME, Shen M (1989) Response to organic enrichment of infaunal macrobenthic communities under salmonid seacages. Mar Biol 103:211-214

- Saito H, Ueno M, Hayashi I, Baden S and others (1998) Temporal fluctuation in the abundance of a semelid bivalve, Theora fragilis (A. Adams) in Maizuru Bay, Sea of Japan. Hydrobiologia 375-376:151-163

Sköld M, Josefson AB, Loo LO (2001) Sigmoidal growth in the brittlestar Amphiura filiformis (Echinodermata: Ophiuroidea). Mar Biol 139:519-526

Snelgrove PVR, Butman CA (1994) Animal-sediment relationships revisited: cause versus effect. Oceanogr Mar Biol Annu Rev 32:111-177

Talman S (1998) The ecology of an exotic marine bivalve, Corbula gibba, in Port Phillip Bay, Victoria, Australia. MAFRI Report 1998, Queenscliff

Tamai K (1996) Temporal tolerance of larval Theora fragilis (Bivalvia: Semelidae) to hypoxic conditions. Fish Sci 62: 996-997

Thrush SF, Whitlach RB (2001) Recovery dynamics in benthic communities: balancing detail with simplification. In: Reise K (ed) Ecological comparisons of sedimentary shores. Springer-Verlag, Berlin, p 297-316

Whitlach RB, Lohrer AM, Thrush SF (2001) Scale-dependent recovery of the benthos: effects of larval and post-larval life stages. In: Aller JY, Woodin SA, Aller RC (eds) Organism-sediment interactions. University of South Carolina Press, Columbia, SC, p 181-197

Wilson JG (1992) Age-specific energetics of reproduction in Nucula turgida (Leckenby and Marshall), a bivalve with lecithotrophic larval development. Invertebr Reprod Dev 22:275-280

Young TP, Chase JM, Huddleston RT (2001) Succession and assembly as conceptual bases in community ecology and ecological restoration. Ecol Res 19:5-19

Zajac RN, Whitlach RB, Thrush SF (1998) Recolonisation and succession in soft-sediment infaunal communities: the spatial scale of controlling factors. Hydrobiologia 375-376: $227-240$

Submitted: May 30, 2006; Accepted: April 22, 2008

Proofs received from author(s): August 4, 2008 